\title{
Reliability, failure probability, and strength of resin-based materials for CAD/CAM restorations
}

\author{
Kiatlin LIM1ㅜ, Adrian U-Jin YAP ${ }^{1,2}$, Shruti Vidhawan AGARWALLA ${ }^{1}$, Keson Beng-Choon TAN ${ }^{1}$, Vinicius ROSA ${ }^{1}$
}

1- Faculty of Dentistry, National University of Singapore, Singapore.

2- JurongHealth Services, Department of Dentistry, Singapore.

Corresponding address: Vinicius Rosa - National University of Singapore, Faculty of Dentistry - 11 Lower Kent Ridge Road, Singapore 119083 - Singapore - Phone: +65 67795555 - ext 1650 - Fax: + 6567785742 - e-mail: denvr@nus.edu.sg

Submitted: December 1t, 2015 - Modification: May 21, 2016 - Accepted: June, 2016

\section{ABSTRACT}

\begin{abstract}
bjective: This study investigated the Weibull parameters and $5 \%$ fracture probability of direct, indirect composites, and CAD/CAM composites. Material and Methods: Discshaped ( $12 \mathrm{~mm}$ diameter $\times 1 \mathrm{~mm}$ thick) specimens were prepared for a direct composite [Z100 (ZO), 3M-ESPE], an indirect laboratory composite [Ceramage (CM), Shofu], and two CAD/CAM composites [Lava Ultimate (LU), 3M ESPE; Vita Enamic (VE), Vita Zahnfabrik] restorations ( $n=30$ for each group). The specimens were polished, stored in distilled water for 24 hours at $37^{\circ} \mathrm{C}$. Weibull parameters $(m=$ modulus of Weibull, $\sigma 0=$ characteristic strength) and flexural strength for $5 \%$ fracture probability ( $\sigma 5 \%)$ were determined using a piston-on-three-balls device at $1 \mathrm{MPa} / \mathrm{s}$ in distilled water. Statistical analysis for biaxial flexural strength analysis were performed either by both one-way ANOVA and Tukey's post hoc $(\alpha=0.05)$ or by Pearson's correlation test. Results: Ranking of $m$ was: VE (19.5), LU (14.5), CM (11.7), and ZO (9.6). Ranking of $\sigma 0$ (MPa) was: LU (218.1), ZO (210.4), CM (209.0), and VE (126.5). б5\% (MPa) was 177.9 for LU, 163.2 for CM, 154.7 for Z0, and 108.7 for VE. There was no significant difference in the $\mathrm{m}$ for ZO, CM, and LU. VE presented the highest $\mathrm{m}$ value and significantly higher than ZO. For $\sigma 0$ and $\sigma 5 \%, Z O, C M$, and LU were similar but higher than VE. Conclusion: The strength characteristics of CAD/ CAM composites vary according to their composition and microstructure. VE presented the lowest strength and highest Weibull modulus among the materials.
\end{abstract}

Keywords: Tensile strength. Reliability and validity. Composite resins. Dental restoration failure. Dental porcelain.

\section{NTRODUCTI ON}

Resin composites are widely used as direct posterior restorative materials due to good aesthetic, biological and physico-mechanical properties ${ }^{16,22,24}$. Resin composites used for direct restorations can present high elastic modulus and fracture strength. In addition, these materials can have a subcritical crack growth susceptibility coefficient as high as 40, resulting in high resistance to slow crack growth15,16,24. However, they have some inherent drawbacks such as polymerisation shrinkage, shrinkage stress, and limited depth of cure. Despite the advances in material technology, bulk fracture persists as one of the major causes of direct composite restoration failure in clinical trials $^{12,24}$.
To overcome some of these limitations, indirect resin composites were introduced ${ }^{14}$. The polymerization protocols of these materials are optimized and often include the use of powerful lights for an extended period of time to achieve high degrees of conversion ${ }^{4,14,21}$. Furthermore, some can be heated to temperatures above the composite's glass transition temperature to allow an increase in polymer chain mobility, leading to additional cross-linking and stress relief $f^{4,14,25}$. Nonetheless, fabrication of indirect composites involves additional laboratory procedures that potentially increase the time required to deliver the restoration to the patient and operational cost. These disadvantages are reduced with CAD/CAM workflows and the introduction of CAD/CAM composite blocks ${ }^{13}$. CAD/ CAM fabrication of dental restorations simplifies 
handling and is less labour intensive, increasing efficiency at a reduced cost ${ }^{5,13}$.

Several resin-based CAD/CAM composites blocks are available with different compositions and microstructure [(e.g. polymer-infiltrated ceramicnetwork (Enamic) and nanoparticle and nanoclusterfilled resin (Lava Ultimate Restorative)]. Although these two materials exhibit smoother milled margins compared to ceramic-based blocks ${ }^{3}$, they present lower flexural modulus, fracture toughness, and flexural strength than glass-ceramic and ceramic materials ${ }^{3,11,20}$.

The measure of structural performance for brittle dental materials is often estimated by their fracture strength values. However, structural performance cannot be directly predicted by strength data, since the latter is a contingent and not an inherent material property ${ }^{17}$. Weibull statistical analysis is largely applied for describing the scatter in fracture strength measurements of brittle materials. It is related to fracture probability and can describe the reliability of materials (e.g. stress required to fracture a given percentage of specimens). In addition, it can be scaled-up considering different specimen size (bulk volume or surface area under stress) ${ }^{8,17}$. The two-parameter Weibull distribution is based on two distinct parameters: Weibull modulus and characteristic strength. The Weibull modulus $(\mathrm{m})$ is a dimensionless material-specific parameter that describes the variation in the strength or asymmetric strength distribution as a result of flaws within the microstructure ${ }^{17}$. Thus, low Weibull modulus values indicate higher scattering for fracture strength data and hence lower reliability. Since it is inversely related to the standard deviation in a normal distribution, high Weibull modulus relates to higher reliability of materials. A higher Weibull modulus equates to a more homogeneous flaw distribution throughout the entire volume, which results in higher structural reliability and lower failure probability $8,16,17,19$.

The objective of this study was to evaluate the biaxial flexural strength and Weibull parameters of CAD/CAM resin-based composites. The hypothesis to be tested is that CAD/CAM materials present higher strength features as compared with direct and indirect composite materials.

\section{MATERIAL AND METHODS}

The materials studied are listed in Figure 1.

Disk shaped specimens ( $12 \mathrm{~mm}$ diam x $1 \mathrm{~mm}$ thick) were prepared as follows:

ZO and CM: specimens were prepared by condensing $\mathrm{ZO}$ and $\mathrm{CM}$ composites into a cylindrical metal mould. A glass slide was used to extrude excess material. ZO specimens were polymerised using a LED light unit (Monitex BlueLEX ${ }^{\mathrm{TM}}$ GT-1200, New Taipei City, Taiwan) at $600 \mathrm{~mW} / \mathrm{cm}^{2}$ for 40 seconds per quadrant. For CM, the uncured discs were placed in a laboratory curing unit (Solidilite V, Shofu, Kyoto, Kyoto Prefecture, Japan) containing four halogen light bulbs of $150 \mathrm{~W}$ each and cured for 5 minutes.

LU and VE: a digital impression (CEREC Omnicam, Sirona, Charlotte, NC, USA) was obtained from a metal cylinder (12 $\mathrm{mm}$ in diameter $\times 14$ $\mathrm{mm}$ in height) and used as a template to mill the blocks (CEREC inLab MC XL milling unit, Sirona, NC, USA). The cylindrical blocks were sliced into $1.1 \mathrm{~mm}$ thick discs (IsoMet 1000 Precision Cutter, Buehler, Bergneustadt, Cologne, Germany).

All the specimens were polished down (Buehler Phoenix Beta Grinder Polisher, Bergneustadt, Cologne, Germany) using a series of sand paper disc of decreasing grits (MicroCut discs, Germany: P1200, P2500 and P4000, 100 rpm / 30 seconds per grit paper) to $1 \mathrm{~mm}$. The final dimensions of specimens were measured at four points diagonally using a digital calliper to ensure a final thickness of $1 \mathrm{~mm}$ and $12 \mathrm{~mm}$ diameter. Specimens were subsequently stored for 24 hours in distilled water at $37^{\circ} \mathrm{C}$ prior to testing.

The biaxial flexural strength of 30 specimens of each material was tested using a piston-on-threeballs device according to Ornaghi, et al. ${ }^{17}$ (2012) at a loading rate of $1 \mathrm{MPa} / \mathrm{s}$. The biaxial flexural strength $\left(\sigma_{\mathrm{BI}}\right)$ was calculated according to Equations 1 to 3 , where $P$ is the fracture load (in N); $b$ is the thickness of the specimen at fracture origin (in $\mathrm{mm}) ; \mathrm{r} 1$ is the radius of the support ball circle ( 5 $\mathrm{mm}) ; \mathrm{r} 2$ is the radius of loaded area $(0.6 \mathrm{~mm})$; and

\begin{tabular}{|c|c|c|c|c|}
\hline Material & Z100 $^{\text {TM }}$ Restorative & Ceramage & Lava $^{\text {TM }}$ Ultimate & Vita Enamic ${ }^{8}$ \\
\hline Group & ZO & CM & LU & VE \\
\hline Manufacturer & 3M ESPE, USA & Shofu, Japan & 3M ESPE, USA & VITA, Germany \\
\hline Material type & Hybrid resin composite & Micro ceramic & Resin nano ceramic & Hybrid ceramic \\
\hline Filler type & Zirconia and silica & Zirconium silicate & $\begin{array}{c}\text { Zirconia and silica particles } \\
\text { agglomerated in clusters }\end{array}$ & Silica and alumina \\
\hline Particle \% weight & 85 & 73 & 80 & 86 \\
\hline Shade & A2 & A2B & A2 & $1 \mathrm{M} 2$ \\
\hline
\end{tabular}

Figure 1- Characteristics of direct (ZO) and indirect (CM, LU and VE) resin composites according to the manufacturers 
$\mathrm{r} 3$ is the radius of the specimen (in $\mathrm{mm}$ ). Poisson's ratio (U) was 0.3 for $\mathrm{ZO}$ and $\mathrm{CM}, 0.43$ for $L U$ and 0.23 for $\mathrm{VE}^{6,16}$.

$$
\sigma_{\mathrm{BI}}=\frac{-0.2387 \mathrm{P}(\mathrm{X}-\mathrm{Y})}{h^{2}}
$$

Equation 1

$$
X=(1+v) \ln \left(\frac{r_{2}}{r_{3}}\right)^{2}+\left[\frac{1-v}{2}\right]\left(\frac{r_{2}}{r_{3}}\right)^{2}
$$

Equation 2

$$
Y=(1+v)\left[1+\ln \left(\frac{r_{1}}{r_{3}}\right)^{2}\right]+(1-v)\left(\frac{r_{1}}{r_{3}}\right)^{2}
$$

\section{Equation 3}

Fracture strength was fitted to the twoparameter Weibull distribution, which is comprised of Weibull modulus $(\mathrm{m})$ and characteristic strength $\left(\sigma_{0}\right)$ obtained according to Equation 4

$$
P_{f}(\sigma)=1-\exp \left[-\left(\frac{\sigma}{\sigma_{0}}\right)^{m}\right]
$$

Equation 4 where Pf is the fracture probability. The parameter $\sigma_{0}$ corresponds to the strength at the failure probability of $63.2 \%$. Based on Equation 4 , the parameter $\sigma_{5 \%}$ was also determined, which corresponds to the strength at the more clinically relevant failure probability of $5 \%$. The Weibull parameters were calculated based on the maximum likelihood method, according to the ASTM C $1239^{2}$ and plotted in addition to their 95\% confidence intervals. Fractured surfaces of randomly selected specimens were examined using optical and scanning electron microscopy (Stereoscan 400, Wetzlar, Giessen, Germany).

Biaxial flexural strength and number of fragments were analyzed by one-way ANOVA and multiple comparisons were performed using Tukey's post hoc test at a pre-set significance level of $5 \%$. Correlation between flexural strength and number of fragments were calculated using Pearson's correlation test.

\section{RESULTS}

The $\mathrm{S}_{\mathrm{BI}}$ obtained for $\mathrm{ZO}, \mathrm{CM}$, and LU were similar, but significantly higher than VE (Table 1 ). There was a positive correlation between $\mathrm{S}_{\mathrm{BI}}$ and the number

Table 1- Mean biaxial flexural strength, MPa (SD), mean number of fractured fragments (SD) and Pearson correlation coefficient. Groups with similar superscript letter are not statistically different $(p<0.05)$

\begin{tabular}{cccc}
\hline Group & sBI(MPa) & Number of fragments & $\begin{array}{c}\text { Pearson correlation coefficient } \\
(\boldsymbol{r})\end{array}$ \\
\hline ZO & $199 \pm 26^{\mathrm{a}}$ & $4.4 \pm 0.9^{\mathrm{a}}$ & 0.65 \\
CM & $200 \pm 21^{\mathrm{a}}$ & $4.2 \pm 1.0^{\mathrm{a}}$ & 0.494 \\
LU & $210 \pm 18^{\mathrm{a}}$ & $3.3 \pm 0.5^{\mathrm{b}}$ & 0.609 \\
VE & $129 \pm 22^{\mathrm{b}}$ & $2.2 \pm 0.4^{\mathrm{c}}$ & 0.761 \\
\hline
\end{tabular}
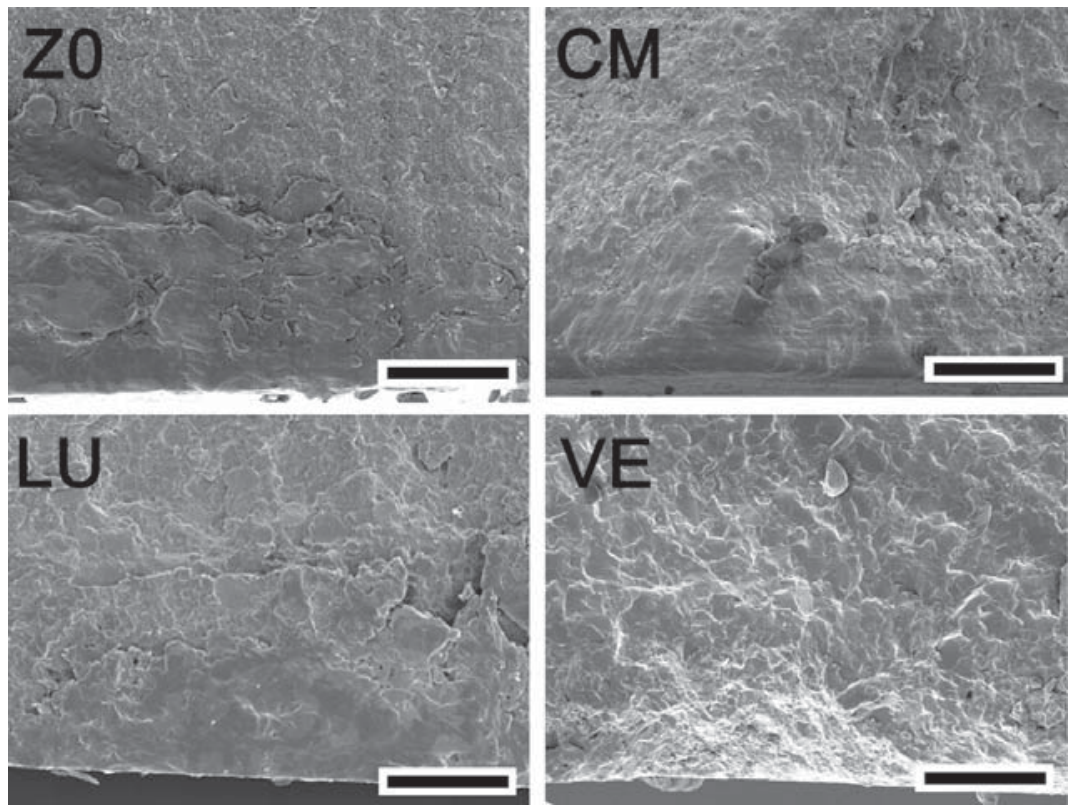

Figure 2- Fracture surfaces of the materials tested (scale bar= $500 \mu \mathrm{m}$ ) 

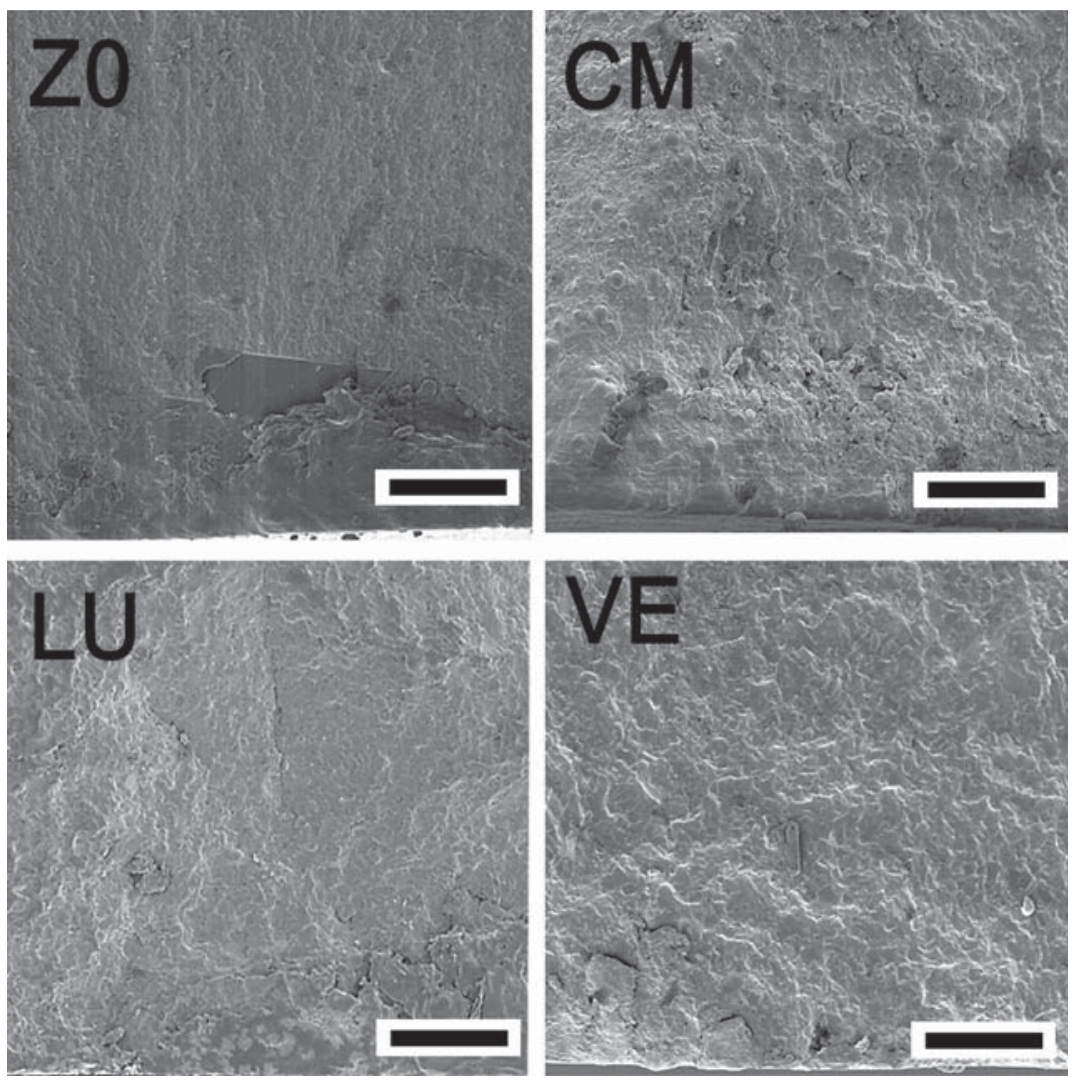

Figure 3- Fracture surfaces of the materials tested (scale bar= $25 \mu \mathrm{m}$ )

Table 2- Weibull parameters (Weibull modulus, m; characteristic strength, $\sigma_{0}$ ), flexural strength at $5 \%$ failure probability $(\sigma 5 \%)$, and their respective $95 \%$ confidence intervals in brackets. Groups with similar superscript letter are not statistically different $(p<0.05)$.

\begin{tabular}{cccc}
\hline Group & $\mathbf{m}$ & $\sigma(\mathbf{M P a})$ & $\sigma 5 \%(\mathbf{M P a})$ \\
\hline Z0 & $9.6(7.0-13.0)^{\mathrm{b}}$ & $210.4(201.4-219.6)^{\mathrm{a}}$ & $154.7(137.8-167.7)$ \\
CM & $11.7(8.5-15.8)^{\mathrm{b}}$ & $209.0(201.5-216.5)^{\mathrm{a}}$ & $163.2(147.4-173.4)$ \\
LU & $14.5(10.6-19.5)^{\mathrm{b}}$ & $218.1(211.9-224.2)^{\mathrm{a}}$ & $177.9(165.0-187.4)$ \\
VE & $19.5(14.1-26.4)^{\mathrm{a}}$ & $126.5(123.8-129.2)^{\mathrm{b}}$ & $108.7(102.6-113.1)$ \\
\hline
\end{tabular}

of fragments. For ZO and CM, 40 and $43 \%$ of the specimens fractured into four pieces and for LU and VE, 57 and $83 \%$ of the discs produced three and two fragments, respectively. Figure 2 and 3 show the fracture surface of selected specimens.

Table 2 shows the Weibull parameters and the respective $95 \%$ confidence intervals. The Weibull plots are shown in Figure 4. There was no significant difference in the $\mathrm{m}$ for $\mathrm{ZO}, \mathrm{CM}$, and $\mathrm{LU}$ as the confidence intervals overlap. VE presented the highest $m$ value and significantly higher than ZO. For $\sigma_{0}$ and $\sigma_{5 \%}, Z O, C M$, and LU were similar, but higher than VE.

There was an average positive correlation between $\sigma_{\mathrm{BI}}$ and the number of fragments for all the materials tested (Table 1 ).

\section{SCUSSI ON}

The hypothesis was rejected, since LU presented similar strength characteristics as CE and ZO. Table 1 shows that the biaxial strength of VE was significantly lower than the other materials tested. Similar trends have been previously reported for flexural strength of $V E^{3,10}$. VE is composed of a porous feldspathic ceramic matrix, infiltrated with a urethane dimethacrylate and triethylene glycol dimethacrylate copolymer. This combination increases the ability to endure mechanical loading by experiencing more elastic deformation before failure $^{3}$. This can possibly be the reason why VE fractured in fewer fragments as compared with the other materials tested (Table 1 ).

Brittle materials, such as ceramics and composites, are very sensitive to the presence of flaws ${ }^{15,19}$. These flaws act as stress concentrators 

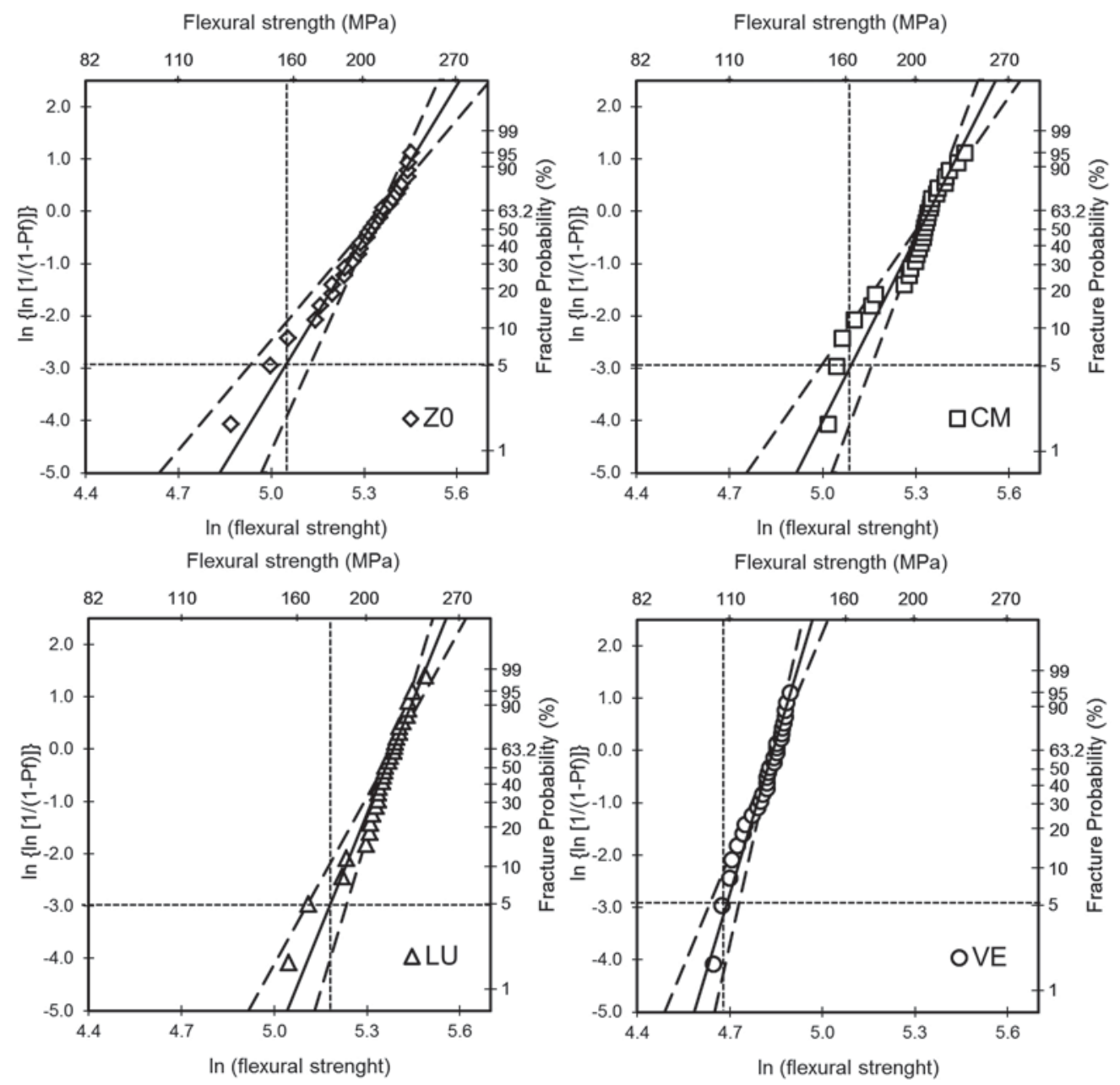

Figure 4- Weibull plot of the materials tested. Dashed lines indicate the $95 \%$ confidence interval of the Weibull modulus. Dotted line indicate flexural strength at $5 \%$ fracture probability $(\sigma 5 \%)$

and are often characterized as scratches, nonuniform matrix and filler interface, foreign bodies, pores, and other innate defects. In direct restorative materials, they can be introduced during the manufacturing process, clinical handling, fabrication or finishing of restorations ${ }^{16}$. The fractographic analysis showed that, typically, the fractures were originated from surface flaws of semi-elliptical shape (Figure 2 and 3). Similar critical defects have been previously observed on fracture surfaces porcelains and resin composites ${ }^{18,19}$. I nterestingly, the Weibull modulus $(m)$ for LU was slightly higher than that obtained for ZO and CM. As the procedures involved to fabricate LU specimens were automated, it may be suggested that the handling of these materials had a minor effect in adding defects to the preexisting flaw population.

The characteristic strength $\left(\sigma_{0}\right)$ corresponds to the stress level for a $63.2 \%$ probability of failure. This location parameter is dependent on the stress configuration and test specimen size. The $\sigma_{0}$ obtained for Z0, CM, and LU were similar (Table 2 ) and at least $65 \%$ higher than the one obtained for VE. Nonetheless, it presented the highest $\mathrm{m}$, resulting in a material with the utmost reliability and predictability for failure among the materials tested. The existence of the polymer phase within the ceramic framework spread the plasticity upon loading, hence increasing the crack resistance with crack extension. This could give a higher observable Weibull modulus, rather than toughening itself, resulting in a material with high $\mathrm{m}$ and moderate $\sigma_{0}^{7,9,11}$.

At a more clinically relevant failure rate $\left(\sigma_{5 \%}\right)$, LU presented the highest value, followed by CM and $Z O$ respectively (Table 2 ). The higher strength for LU may be related to its microstructure, which is composed of 0.6-1.0 $\mu \mathrm{m}$ aggregated zirconia/ silica clusters (consisting of $20 \mathrm{~nm}$ silica and 4- 11 $\mathrm{nm}$ zirconia particles); non-agglomerated/nonaggregated $20 \mathrm{~nm}$ silica nanoparticles; and nonagglomerated/non-aggregated 4 to $11 \mathrm{~nm}$ zirconia nanoparticles ${ }^{1}$. The wider granulometric distribution can amplify the likelihood for crack deflection and increased flexural strength ${ }^{16,24}$. 


\section{CONCLUSI ON}

The strength characteristics of CAD/CAM composites vary according to their composition and microstructure. VE presented the lowest strength and highest Weibull modulus among the materials. LU and CM presented similar strength parameters compared with the direct restorative material tested.

\section{ACKNOWLEDGEMENTS}

This research was supported by grants R-221000-061-133 (VR) and R-221-000-046-101 (VR) from the National University of Singapore.

\section{CONFLI CT OF I NTEREST}

The authors have no other relevant affiliations or financial involvement with any organization or entity with a financial interest in or financial conflict with the subject matter or materials discussed in the manuscript.

\section{REFERENCES}

1- 3M ESPE. Lava ${ }^{T M}$ ultimate CAD/CAM restorative technical product profile [online]. St. Paul: 3M ESPE; 2011 [cited March $4^{\text {th }}$, 2016]. Available from: http://www.D-way.Cz/data/product/13/23/ files/lava_ult_tpp.Pdf.

2- American Society for Testing Materials - ASTM. C1239 reporting uniaxial strength data and estimating weibull distribution parameters for advanced ceramics. West Conshohocken: ASTM; 2000.

3- Awada A, Nathanson D. Mechanical properties of resinceramic CAD/CAM restorative materials. J Prosthet Dent. 2015; 114(4): 587-93.

4- Bagis YH, Rueggeberg FA. The effect of post-cure heating on residual, unreacted monomer in a commercial resin composite. Dent Mater. 2000; 16(4):244-7.

5- Davidowitz G, Kotick PG. The use of CAD/CAM in dentistry. Dent Clin North Am. 2011;55(3): 559-70.

6- Della Bona A, Corazza PH, Zhang Y. Characterization of a polymer-infiltrated ceramic-network material. Dent Mater. 2014;30(5): 564-9.

7- Dugdale DS. Yielding of steel sheets containing slits. J Mechan Phys Solids. 1960;8(1): 100-4.

8- Kelly J R. Perspectives on strength. Dent Mater. 1995; 11(2): 10310.

9- Kendall K, Alford NM, Tan SR, Birchall JD. Influence of toughness on weibull modulus of ceramic bending strength. J Mater Res. 1986; 1(1): 120-3
10- Lauvahutanon S, Takahashi H, Shiozawa M, I wasaki N, Asakawa Y, Oki M, et al. Mechanical properties of composite resin blocks for CAD/CAM. Dent Mater J. 2014;33(5): 705-10.

11- Leung BT, Tsoi JK, Matinlinna JP, Pow EH. Comparison of mechanical properties of three machinable ceramics with an experimental fluorophlogopite glass ceramic. J Prosthet Dent. 2015; 114(3): 440-6.

12- Manhart J, Chen H, Hamm G, Hickel R. Buonocore Memorial Lecture. Review of the clinical survival of direct and indirect restorations in posterior teeth of the permanent dentition. Oper Dent. 2004;29(5): 481-508.

13- Mörmann WH, Bindl A. All-ceramic, chair-side computer-aided design/computer-aided machining restorations. Dent Clin North Am. 2002; 46(2): 405-26.

14- Nandini S. Indirect resin composites. J Conserv Dent. 2010; 13(4): 184-94.

15- Ornaghi BP, Meier MM, Lohbauer U, Braga RR. Fracture toughness and cyclic fatigue resistance of resin composites with different filler size distributions. Dent Mater. 2014;30(7):742-51. 16- Ornaghi BP, Meier MM, Rosa V, Cesar PF, Lohbauer U, Braga RR. Subcritical crack growth and in vitro lifetime prediction of resin composites with different filler distributions. Dent Mater. 2012; 28(9): 985-95.

17- Quinn JB, Quinn GD. A practical and systematic review of Weibull statistics for reporting strengths of dental materials. Dent Mater. 2010; 26(2): 135-47.

18- Rodrigues SA Jr, Ferracane JL, Della Bona A. Influence of surface treatments on the bond strength of repaired resin composite restorative materials. Dent Mater. 2009; 25(4):442-51. 19- Rosa V, Yoshimura HN, Pinto MM, Fredericci C, Cesar PF. Effect of ion exchange on strength and slow crack growth of a dental porcelain. Dent Mater. 2009;25(6):736-43.

20- Ruse ND, Sadoun MJ. Resin-composite blocks for dental CAD/ CAM applications. J Dent Res. 2014;93(12): 1232-4.

21- Sadowsky SJ. An overview of treatment considerations for esthetic restorations: a review of the literature. J Prosthet Dent. 2006; 96(6): 433-42

22- Van Dijken JW, Pallesen U. A randomized 10-year prospective follow-up of class ii nanohybrid and conventional hybrid resin composite restorations. I Adhes Dent. 2014;16(6): 585-92.

23- Van Nieuwenhuysen JP, D'Hoore W, Carvalho J, Qvist V. Longterm evaluation of extensive restorations in permanent teeth. J Dent. 2003; 31(6): 395-405.

24- Vidhawan SA, Yap AU, Ornaghi BP, Banas A, Banas K, Neo JC, et al. Fatigue stipulation of bulk-fill composites: an in vitro appraisal. Dent Mater. 2015;31(9): 1068-74.

25- Viljanen EK, Skrifvars M, Vallittu PK. Dendritic copolymers and particulate filler composites for dental applications: degree of conversion and thermal properties. Dent Mater. 2007; 23(11): 1420-7. 